\title{
Microstructure, microhardness, tensile, electrical, and thermal properties of the Al-Mn- $x$ Si ternary alloys
}

\author{
H. Kaya ${ }^{1 *}$, E. Çadırlı ${ }^{2}$ U. Büyük ${ }^{1}$ \\ ${ }^{1}$ Erciyes University, Education Faculty, Department of Science Education, Kayseri, Turkey \\ ${ }^{2}$ Niğde Ömer Halisdemir University, Arts and Sciences Faculty, Department of Physics, Niğde, Turkey
}

Received 2 February 2020, received in revised form 23 May 2020, accepted 26 May 2020

\begin{abstract}
The effect of Si content $(0.5,1.5$, and $5 \mathrm{wt} . \%)$ and growth velocity on the microstructure, microhardness, ultimate tensile strength, electrical resistivity, enthalpy, and specific heat properties of the directionally solidified Al-Mn eutectic alloy have been investigated. Al-1.94Mn- $x \mathrm{Si}$ $(x=0.5,1.5,5$ wt.\%) samples were prepared from pure metals (99.99\% purity) under the vacuum. These alloys were directionally solidified under constant temperature gradient $G$ $\left(4.9 \mathrm{~K} \mathrm{~mm}^{-1}\right.$ ) and different growth velocities $V$ (from 8.3 to $978 \mu \mathrm{m} \mathrm{s}^{-1}$ ) in a Bridgman-type growth apparatus. Measurements of primary dendrite arm spacing $(\lambda)$, microhardness (HV), ultimate tensile strength (UTS) and electrical resistivity $(\rho)$ of the samples were carried out and then expressed as functions of growth velocity and $\mathrm{Si}$ content $\left(C_{\mathrm{o}}\right)$. Additionally, the enthalpy of fusion $(\Delta H)$ and specific heat capacity $\left(C_{\mathrm{p}}\right)$ for the same alloys were determined by a differential scanning calorimeter (DSC) from the heating curves. It has been found that the values of HV, UTS, and $\rho$ increase with increasing values of $V$ and $C_{\mathrm{o}}$. On the contrary, the values of $\lambda$ decrease with increasing $V$. The increasing Si content in Al-Mn leads to a decrease of $\Delta H$ and $C_{\mathrm{p}}$.
\end{abstract}

K e y w or d s: Al-Mn-Si alloys, solidification, microstructure, mechanical properties, thermal properties, electrical resistivity

\section{Introduction}

Al-Mn alloys are known to have good formability with high enough strength [1], good mechanical properties, good corrosion resistance, ease of welding and brazing. They are convenient for many engineering, chemical, transportation, building, desalination, marine, and food handling applications. The size, shape, and distribution of intermetallic compounds are known to affect the recrystallized grain size of Al-Mn alloys [2-4]. Because these alloys are generally used in the form of sheet, strip or foil, the problem of grain refinement assumes added importance. On the other hand, Al-Si alloys are an essential class of aluminum die casting alloys having wide ranging applications in industry. The application area of an alloy is specified by the physical properties of the casting, which are influenced by the chemical composition and microstructure [5-8].

Within the past few years, research activities dedi- cated to multiphase solidification of ternary and multicomponent alloys have reached considerable levels [9-11]. Multiphase solidification of multicomponent materials attracts pronounced academic interest as well. The study of the solidification behavior of multicomponent and multiphase systems is an important point in understanding the different properties of these materials.

It is well known that the physical properties (mechanical, electrical, thermal, etc.) of metallic materials are affected by their morphology. The microstructure evolution during solidification depends on the composition, melting conditions, solidification velocity, casting process, and the applied thermal treatment $[5,7,10,11]$. When an alloy is solidified, the most frequently observed solid morphology is eutectic or dendritic microstructures [12]. The microstructure parameters characterize microstructures. Numerous solidification studies have been reported with a view to describing the microstructure parameters

*Corresponding author: tel.: +90-352-4376666 ext. 37091; fax: +90-352-4374933; e-mail address: hasankaya@erciyes.edu.tr 
as a function of growth velocity $[13,14]$.

The microstructural, mechanical, electrical, and thermal properties of directionally solidified Al-based alloys which are important commercial materials have been reported in several investigations [5-14], but the results differ from each other.

This work aimed to experimentally investigate the effect of Si content $(\mathrm{Co})$ and growth velocity $(V)$ on the microstructure (primary dendritic spacing, $\lambda$ ), microhardness (HV), ultimate tensile strength (UTS), electrical resistivity $(\rho)$, enthalpy of fusion $(\Delta H)$, and specific heat capacity $\left(C_{\mathrm{p}}\right)$ of the directionally solidified Al-1.94Mn- $x \mathrm{Si}(x=0.5,1.5,5 \mathrm{wt} . \%)$ ternary alloys. In addition, another aim is to examine the possible effects of the composition and temperature on the thermal $\left(\Delta H\right.$ and $\left.C_{\mathrm{p}}\right)$ and electrical $(\rho)$ properties.

\section{Materials and methods}

\subsection{Sample preparation}

Al-1.94Mn- $x \mathrm{Si}(x=0.5,1.5,5$ wt. $\%)$ alloys have been prepared under vacuum atmosphere by using 99.99\% purity metals. After allowing time for melt homogenization, the molten alloy was poured into the hot filling furnace. The molten alloy was directionally solidified from bottom to top to ensure that the crucible was full. Then, each sample was positioned in a Bridgman type furnace in a graphite cylinder. In this technique, the specimens were heated to about $100 \mathrm{~K}$ above the melting temperature. After stabilizing the thermal conditions in the furnace, the samples were grown by pulling it downwards at different growth conditions under an argon atmosphere. The samples were solidified under steady-state conditions at a constant temperature gradient, and a wide range of growth velocities $\left(8.3-978 \mu \mathrm{m} \mathrm{s}^{-1}\right)$ in the Bridgman-type growth apparatus described elsewhere [7-13]. After 10-12 cm steady-state growth, the samples were quenched by rapidly pulling them down into the water reservoir. The temperature of water in the reservoir was kept at $283 \mathrm{~K}$ by using a heating/refrigerating circulating bath. The sample temperature was controlled with an accuracy of $\pm 0.1 \mathrm{~K}$ using a temperature controller. In order to see the effect of growth velocity and Si content on microstructure and mechanical properties, directional solidification experiments were done at four different growth velocities for each $\mathrm{Al}-\mathrm{Mn}-x \mathrm{Si}$ alloy.

\subsection{Measurement of temperature gradient and growth velocity}

The temperatures in the samples were measured by three K-type thermocouples. All the thermocouples were connected to the measurement unit consist- ing of data-logger and computer. The cooling curves were recorded with a data-logger via computer during the solidification process (details are given in [7]). When the second thermocouple was at the solid/liquid interface, the temperature difference $(\Delta T)$ between the first and second thermocouples was read from the data-logger record. The temperature gradient in liquid at the solid-liquid interface $(G=\Delta T / \Delta X)$ for each sample was calculated from three cooling curves using the measured value of $\Delta T$ and the value of $\Delta X$.

\subsection{Microstructure characterization}

The quenched samples were removed from the graphite crucible and cut into lengths of typically $8 \mathrm{~mm}$. The longitudinal and transverse sections of the ground samples were then cold mounted with epoxyresin. The longitudinal and transverse sections were ground flat with $(180,500,1000,2500$, and 4000) grit $\mathrm{SiC}$ paper, and then polished with $(6,3,1,0.25$, and $0.05) \mu \mathrm{m}$ diamond paste. After polishing, the samples were etched $\left(20 \mathrm{ml}\right.$ distilled $\mathrm{H}_{2} \mathrm{O}+20 \mathrm{ml} \mathrm{HNO}_{3}+$ $20 \mathrm{ml} \mathrm{HCl}+5 \mathrm{ml} \mathrm{HF}$ from 5 to $8 \mathrm{~s}$ ). The microstructures of the samples were revealed and photographed by the SEM (LEO model). Primary dendrite arm spacing was measured with the Adobe Photoshop CS3 program. Chemical composition analysis of the samples was carried out with the same SEM equipped with an energy dispersive X-ray (EDX) spectrometer at $20 \mathrm{keV}$ using the X-ray lines as well as a computer-controlled image system.

\subsection{Measurements of dendritic spacing}

Two different methods were used to measure primary dendrite arm spacing, $\lambda_{1}$ [15]. In the first method, the primary dendrite arm spacing, $\lambda_{1 \mathrm{~L}}$, was obtained by measuring the distance between the nearest two dendrites tips (Fig. 1a) on a longitudinal section. The second method is the area counting method [14]. The values of $\lambda_{1 \mathrm{~T}}$ were measured in the transverse section of the sample (see Fig. 1). In this method the average primary dendrite arm spacing, $\lambda_{1 \mathrm{~T}}$, was determined from

$$
\lambda_{\mathrm{T}}=\frac{1}{M}\left(\frac{A}{N}\right)^{0.5},
$$

where $M$ is the magnification factor, $A$ is the total specimen cross-sectional area, and $N$ is the number of primary dendrites on the cross-section. $\lambda$ is arithmetic average value of $\lambda_{1 \mathrm{~L}}$ and $\lambda_{1 \mathrm{~T}}$.

\subsection{Measurements of microhardness, ultimate tensile strength, and electrical resistivity}

Microhardness values of the samples were measured by using a DuraScan digital hardness test de- 


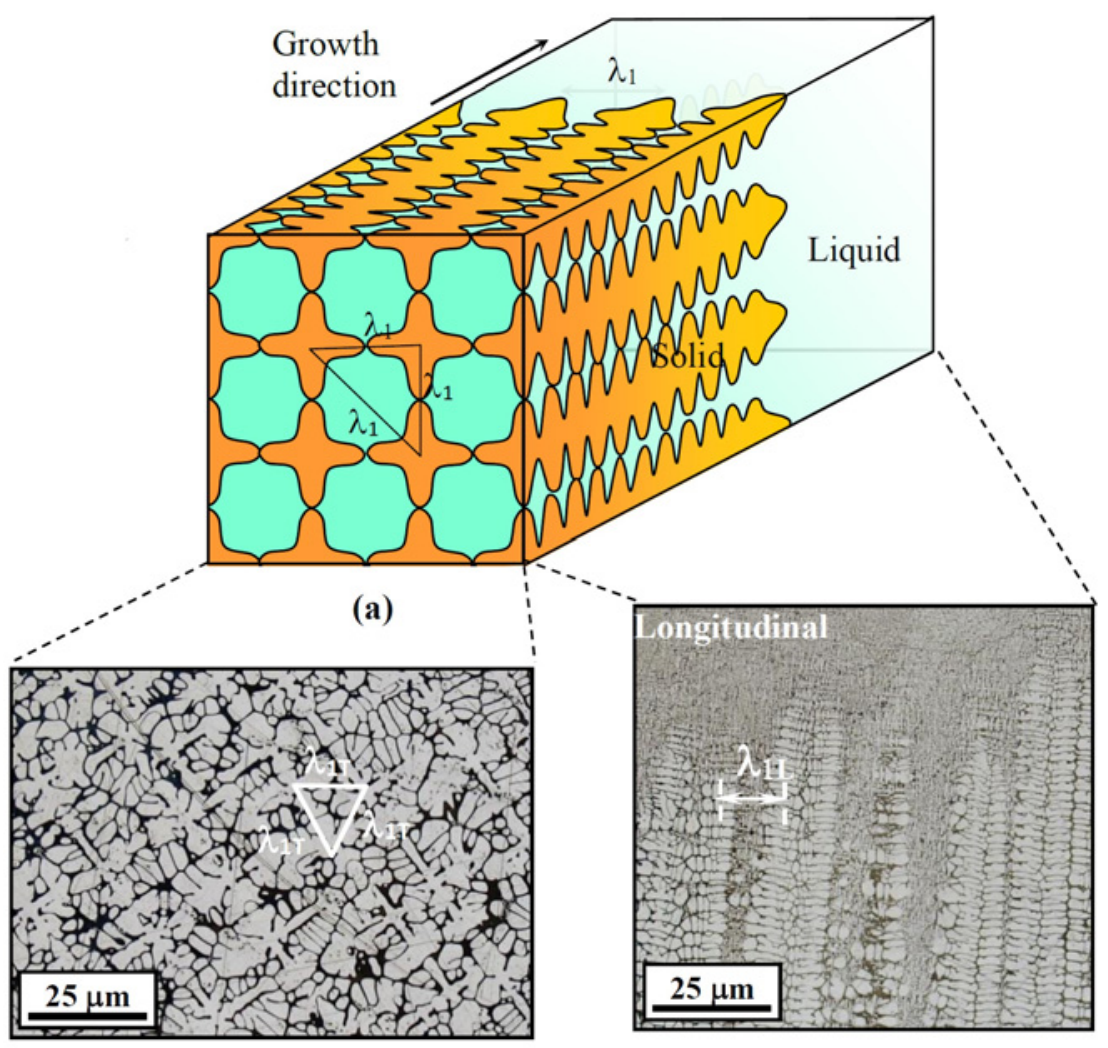

(b)

(c)

Fig. 1. Schematic illustration of the dendritic spacing measurements in (a) longitudinal and transverse sections, (b) transverse section, and (c) longitudinal section.

vice. In this work, $100 \mathrm{~g}$ load was applied to the sample for $10 \mathrm{~s}$. After taking about 20 measurements from the longitudinal and transverse sections of each sample, the average value of these measurements was taken. The tensile tests were performed at a strain rate of $10^{-3} \mathrm{~s}^{-1}$ with a Shimadzu $A G-X D$ universal testing machine. Cylindrical tensile specimens with a diameter of $4 \mathrm{~mm}$ and a gauge length of $50 \mathrm{~mm}$ were machined from the directionally solidified samples prepared at different growth velocities.

Electrical resistivity of the directionally solidified samples was measured by the DC four-point probe method at temperatures ranging from room temperature to $590 \mathrm{~K}$.

\subsection{Determination of enthalpy and specific heat capacity}

The thermal properties (enthalpy of fusion and the specific heat capacity) of the Al-Mn- $x \mathrm{Si}$ specimens were measured by DSC thermal analysis. The instrument measures the difference between heat flow from the sample and reference (empty crucible) sides of a sensor as a function of temperature. The specific heat capacity measurements were performed following the standard ASTM E-1269-05. This method consists of heating a blank (baseline), the sample, and a sapphire disk (reference material for $C_{\mathrm{p}}$ measurements) through the same temperature range at a fixed velocity in a controlled atmosphere (nitrogen flow as protective gas). The difference between the sample curve and the baseline curve was measured in milliwatts and converted to specific heat as follows [16]:

$$
C_{\mathrm{p}}=\frac{\mathrm{d} Q}{\mathrm{~d} t} \frac{1}{m \beta},
$$

where $\mathrm{d} Q / \mathrm{d} t$ is the heat flow, $m$ is the mass of the sample in $(\mathrm{g})$, and $\beta$ is the heating velocity in $\left(\mathrm{K} \mathrm{min}^{-1}\right)$.

The Al-Mn- $x$ Si cast alloys were heated with a heating velocity of $10 \mathrm{~K} \mathrm{~min}^{-1}$ from 293 to $1200 \mathrm{~K}$. The values of the enthalpy of fusion and the specific heat capacity were also calculated from the curves of the heat flow.

\section{Results and discussion}

\subsection{Microstructural characterization}

The microstructure of Al-Mn- $x \mathrm{Si}$ alloys consists of Al-rich dendrites, as shown in Fig. 2. The EDX 

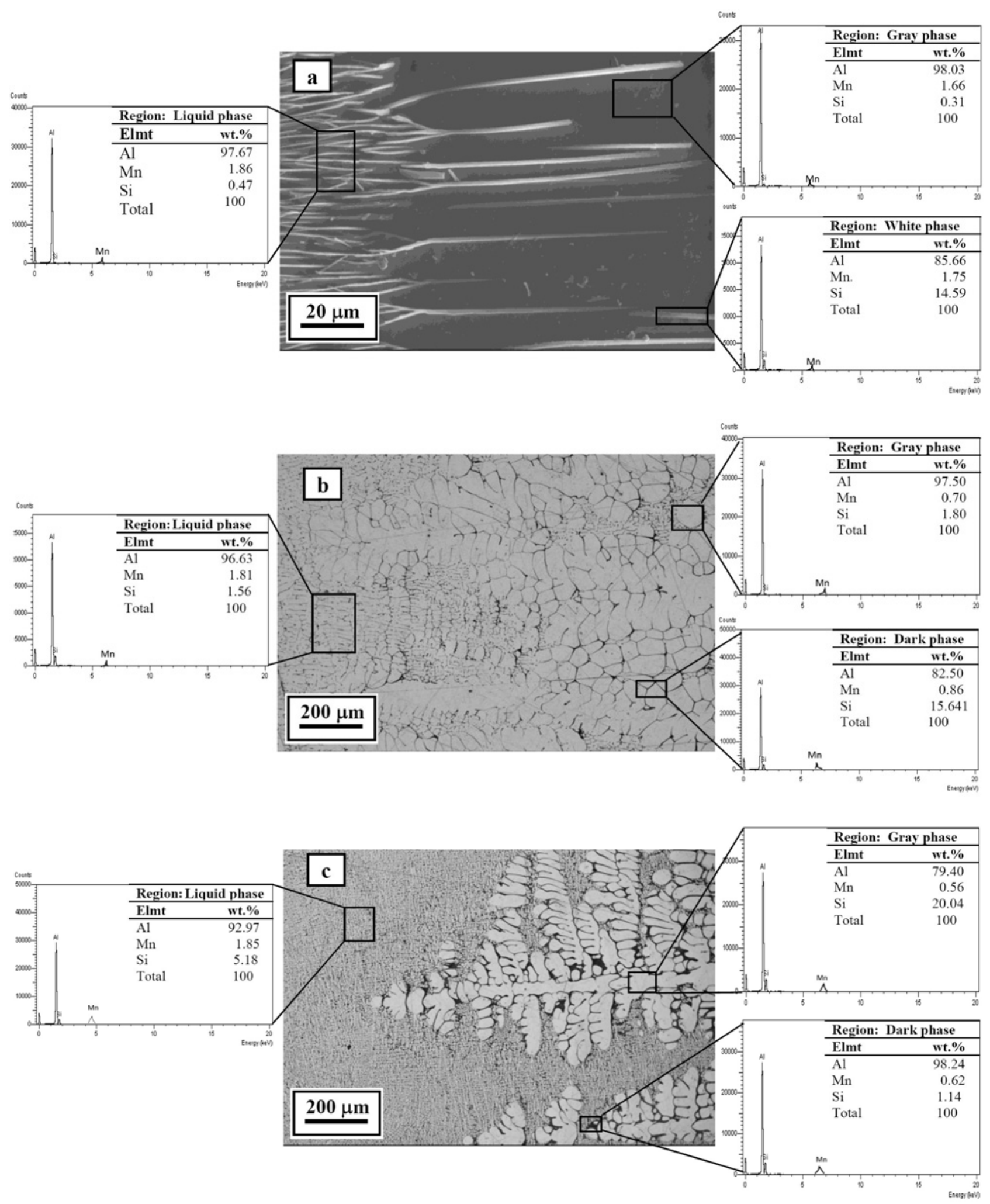

Fig. 2. The chemical composition analysis and growth microstructures of the Al-Mn- $x$ Si alloys: (a) Al-1.94Mn-0.5Si, (b) Al-1.94Mn-1.5Si, and (c) Al-1.94Mn-5Si.

analysis in Fig. 2 indicates that the chemical composition of the quenched liquid phase is very close to the nominal composition, and the inter-dendritic gray phase belongs to the Al-rich matrix phase. According to the EDX results, the measurements taken from the liquid region of Al-1.86Mn-0.47Si, Al-1.81Mn- 

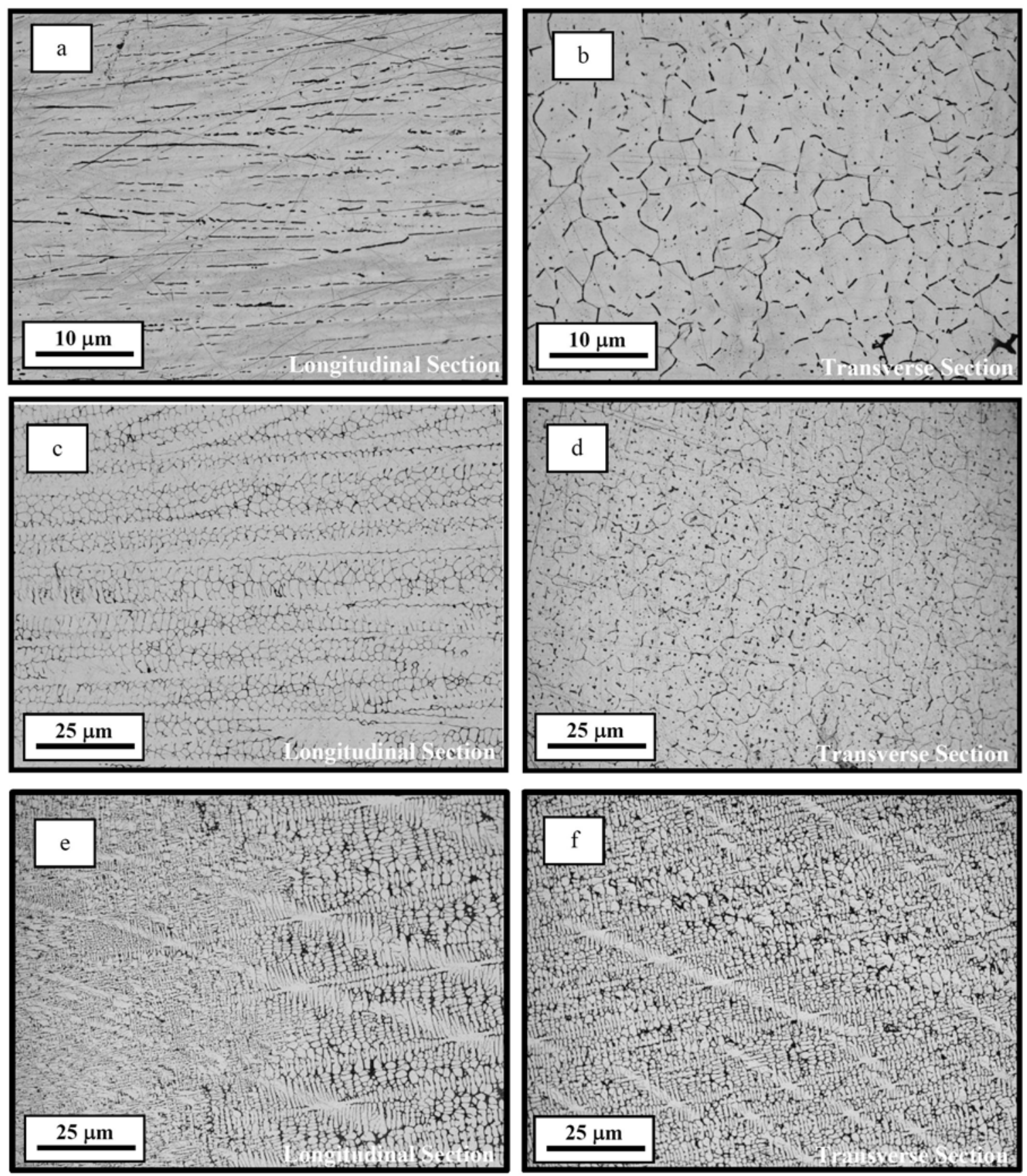

Fig. 3. Typical optical micrographs of the directionally solidified Al-1.94Mn- $x$ Si alloys at $V=978 \mu \mathrm{m} \mathrm{s}^{-1}$ and $G=$ $4.9 \mathrm{~K} \mathrm{~mm}^{-1}$ : (a) and (b) Al-1.94Mn-0.5Si, (c) and (d) Al-1.94Mn-1.5Si, (e) and (f) Al-1.94Mn-5Si.

-1.56Si, and Al-1.85Mn-5.18Si (wt.\%) are very close to the nominal composition of Al-1.94Mn- $x \mathrm{Si}(x=$ $0.5,1.5,5$ wt.\%) alloys, respectively. The chemical composition of dendrite trunks in the solid phase (Fig. 2a) are Al-1.66Mn-0.31Si, Al-07Mn-1.80Si, and Al-0.56Mn-20.04Si (wt.\%). As can be seen from Figs. 2b,c, the amounts of Si in the dendrite trunks increased and contributed to the formation of Si-rich regions.

\subsection{The effect of growth velocity and Si content on microstructure}

The Al-Mn- $x$ Si bulk samples were directionally solidified under a constant temperature gradient $G$ $\left(4.9 \mathrm{~K} \mathrm{~mm}^{-1}\right)$ and different growth velocities $V$ (from 8.3 to $978 \mu \mathrm{m} \mathrm{s}^{-1}$ ). Microstructure features (Figs. 2, 3 ) of the grown samples were analyzed, and the influence of the growth velocity on the primary dendritic 


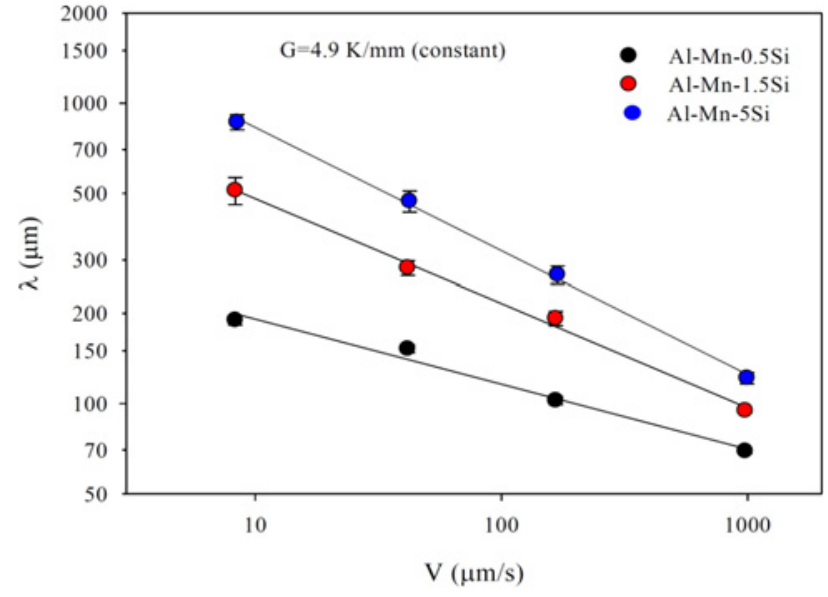

Fig. 4. Variation of the dendritic spacing with the growth velocity for $\mathrm{Al}-\mathrm{Mn}$ alloys containing $0.5 \mathrm{Si}, 1.5 \mathrm{Si}$, and $5 \mathrm{Si}$.

spacing $(\lambda)$ was examined. From the experimental results, the relationship between primary dendritic spacing and the growth velocity can be written as:

$$
\lambda=k_{1} V^{-a}
$$

where $k_{1}$ is the proportionality constant, and $a$ is the exponent value of $V$. As can be seen from Fig. 4, the values of $\lambda$ decrease with increasing values of $V$.

As can be seen from Fig. 4, the values of $\lambda$ decrease with the increasing growth velocity and increase with the increasing Si content. The exponent values of $V$ relating to $\lambda$ were obtained to be $0.22,0.35$, and 0.41 for $0.5 \mathrm{Si}, 1.5 \mathrm{Si}$, and $5 \mathrm{Si}$ in the $\mathrm{Al}-1.94 \mathrm{Mn}$ alloys, respectively. The exponent values $a$ are in a good agreement with the values of $0.30,0.24,0.25,0.24$, and 0.28 obtained by Fan et al. [17], Lapin et al. [18] or Kaya et al. $[19,20]$ for Al-based alloys prepared under similar solidification conditions. The exponent values $a$ are also close to the theoretical value of 0.25 predicted by the Hunt [21], Kurz-Fisher [22], and Trivedi [23] models for binary dendritic growth. However, until now, there has not been any accepted theoretical model for ternary alloys in the literature to be compared with the experimental results.

As shown in Fig. 4, the $\lambda$ values increase with the increasing Si content for the same growth velocities. At the growth velocities of $8.3 \mu \mathrm{m} \mathrm{s}^{-1}$, the $\lambda$ values are measured to be 190,511 , and $867 \mu \mathrm{m}$ for $0.5 \mathrm{Si}$, $1.5 \mathrm{Si}$, and $5 \mathrm{Si}$ alloys, respectively.

\subsection{The effect of growth velocity and $S i$ content on microhardness and ultimate tensile strength}

The Al-Mn- $x$ Si samples were solidified at different growth velocities ranging from 8.3 to $978 \mu \mathrm{m} \mathrm{s}^{-1}$. In this work, microhardness measurements were made on

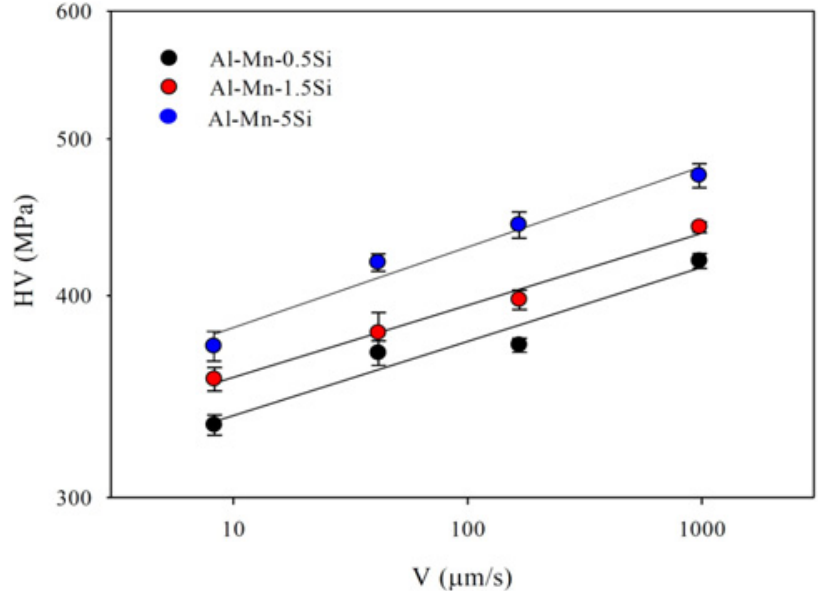

Fig. 5. Variation of the microhardness with the growth velocity for $\mathrm{Al}-\mathrm{Mn}$ alloys containing $0.5 \mathrm{Si}, 1.5 \mathrm{Si}$, and $5 \mathrm{Si}$.

transverse sections at about 30 different randomly selected regions. As shown in Fig. 5, an increase in the growth velocity leads to an increase in the microhardness. From the experimental results, the relationship between microhardness (HV) and growth velocity can be written as:

$$
\mathrm{HV}=k_{2} V^{b}
$$

where $k_{2}$ is the constant and $b$ is the exponent of the growth velocity $V$.

It is found that the increasing growth velocity from 8.3 to $978 \mu \mathrm{m} \mathrm{s}^{-1}$ leads to an increase in microhardness values from 326 to $468 \mathrm{MPa}$ depending on the $\mathrm{Si}$ content. The exponent values $b$ are found to be $0.05,0.03$, and 0.05 for the $0.5 \mathrm{Si}, 1.5 \mathrm{Si}$, and $5 \mathrm{Si}$ alloys, respectively. The exponent values $b$ are in a good agreement with the reported values ranging from 0.03 to 0.08 published by Kaya et al. [24], Guo et al. [25], Lapin et al. [26], and Perdrix et al. [27] for ternary and multicomponent alloys prepared under similar solidification conditions.

Figure 5 shows that the $\mathrm{HV}$ values increase with the increasing $C_{\mathrm{o}}$. At the growth velocity of $8.3 \mathrm{~mm} \mathrm{~s}^{-1}$, the values of $\mathrm{HV}$ are measured to be $326 \mathrm{MPa}, 348 \mathrm{MPa}$, and $367 \mathrm{MPa}$ for $0.5 \mathrm{Si}, 1.5 \mathrm{Si}$, and $5 \mathrm{Si}$ alloys, respectively. Similarly, at the growth velocity of $978 \mu \mathrm{m} \mathrm{s}^{-1}$, the microhardness values increase from 420 to $477 \mathrm{MPa}$ with the increasing Si content from 0.5 to 5 wt.\%.

The effect of growth velocity and $\mathrm{Si}$ content on the ultimate tensile strength of Al-Mn- $x \mathrm{Si}$ alloys is presented in Fig. 6. The UTS values change with growth velocity and $\mathrm{Si}$ content. While the maximum value of UTS $=165.4 \mathrm{MPa}$ is measured for the $\mathrm{Al}-\mathrm{Mn}-5 \mathrm{Si}$ alloy at $978 \mu \mathrm{m} \mathrm{s}^{-1}$ (Fig. 6c), the minimum value of $59.4 \mathrm{MPa}$ is measured for $\mathrm{Al}-\mathrm{Mn}-0.5 \mathrm{Si}$ at $8.3 \mu \mathrm{m} \mathrm{s}^{-1}$ (Fig. 6a). 

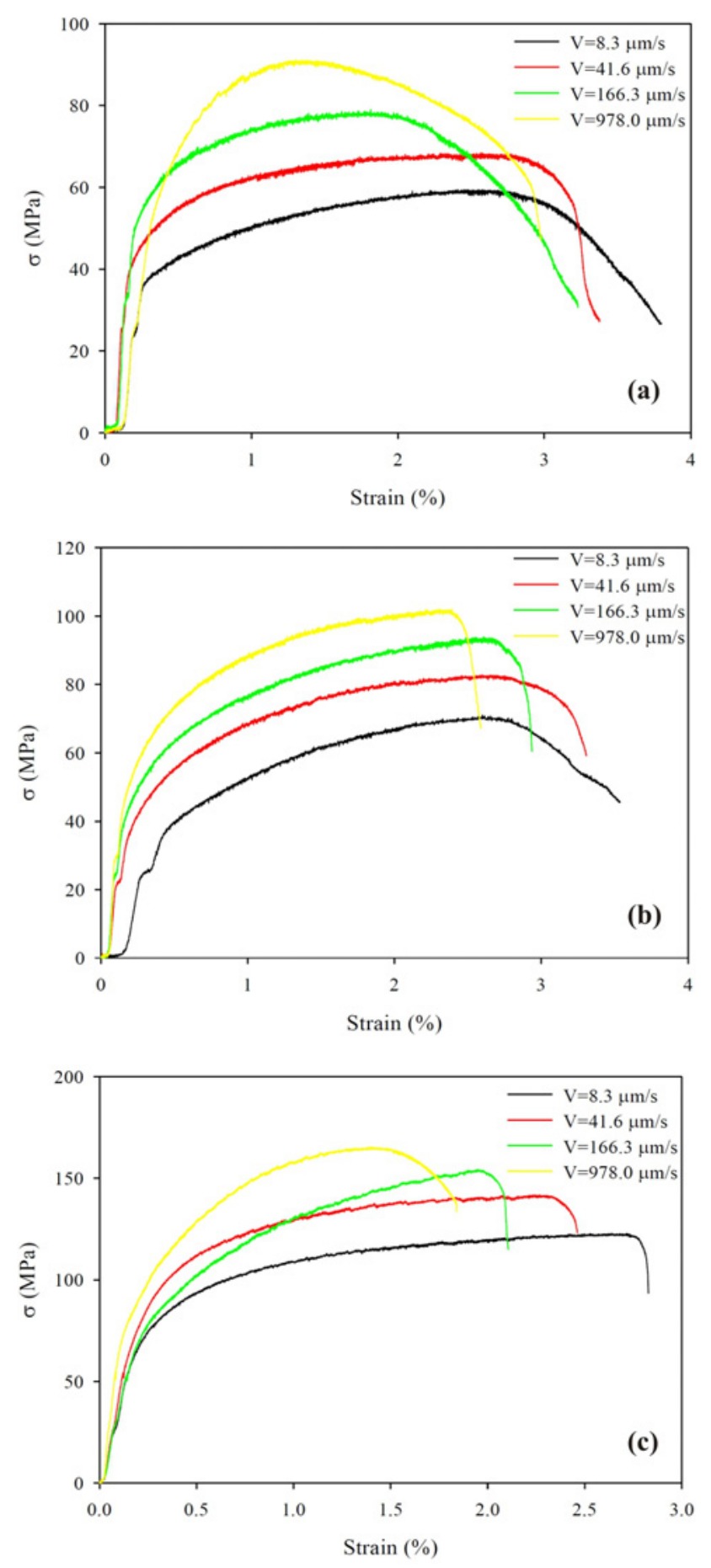

Fig. 6. Strength-strain curves of Al-Mn alloys containing: (a) $0.5 \mathrm{Si}$, (b) $1.5 \mathrm{Si}$, and (c) $5 \mathrm{Si}$.

In this study, the values of UTS were measured on cylindrical samples ( $4 \mathrm{~mm}$ after the directionally solidified). After the measurements, the average ultimate tensile strength values were obtained for each alloy. It can be seen from Fig. 7 that an increase in $V$ and $C_{\mathrm{o}}$ leads to an increase in the ultimate tensile strength.

From experimental results, the dependence of UTS
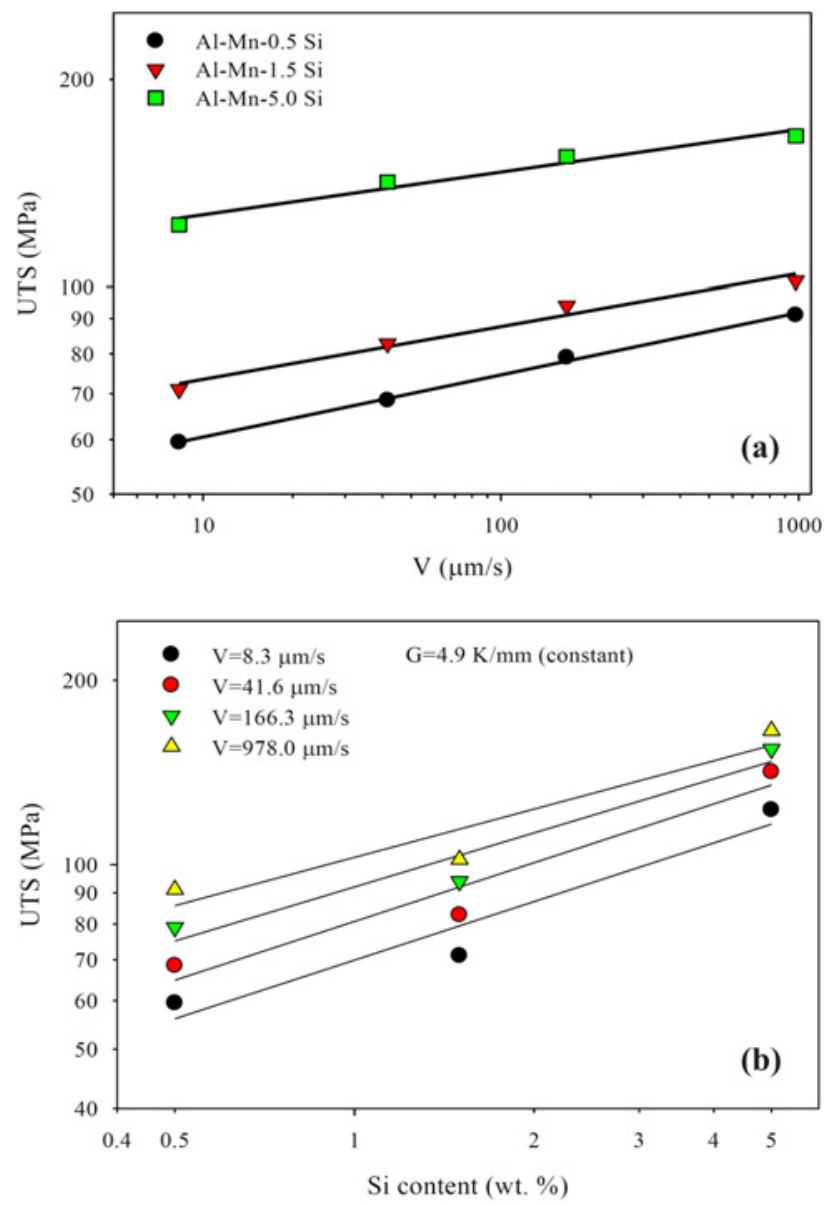

Fig. 7. Variation of ultimate tensile strength versus growth velocity (a) and variation of ultimate tensile strength versus Si content (b).

$(\sigma)$ on $V$ can be expressed as:

$$
\sigma=k_{3} V^{c}
$$

where $k_{3}$ is the constant and $c$ is the exponent of the growth velocity.

The values of UTS increase with increasing growth velocity (Fig. 7b). It was found that the increasing $V$ from 8.3 to $978.0 \mu \mathrm{m} \mathrm{s}^{-1}$ leads to an increase of the maximum ultimate tensile strength values from 59.4 to $165.4 \mathrm{MPa}$ for the Al-Mn alloy with the addition of $5 \mathrm{Si}$. The values of HV and UTS increase with the increasing growth velocity and Si content. Especially, the Al-1.94Mn-5Si alloy has the highest values of HV and UTS. Homogeneous distribution of silicon particles formed along the dendritic regions improves the microhardness and ultimate tensile strength of the matrix. The exponent values $c$ are found to be 0.09 , 0.08 , and 0.06 for $0.5 \mathrm{Si}, 1.5 \mathrm{Si}$, and $5 \mathrm{Si}$ alloys, respectively. The exponent values $c$ are in a good agreement with the values ranging from 0.04 to 0.09 reported by Çadırlı et al. [28], Kaya et al. [24, 29, 30] for 

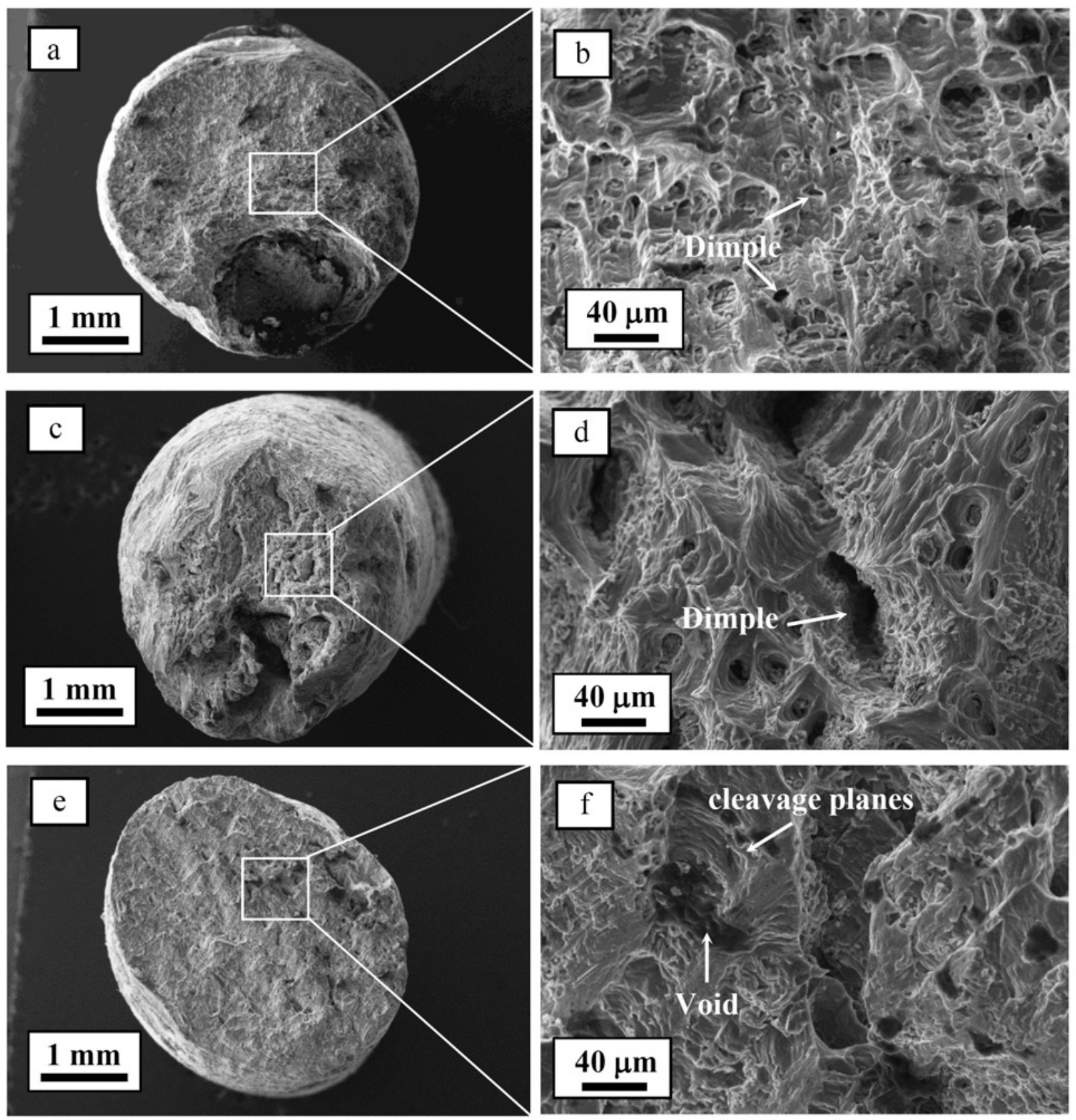

Fig. 8. General morphology and high magnification views of the fracture surface of Al-Mn-Si alloys: (a) and (b) Al-Mn-0.5Si, (c) and (d) Al-Mn-1.5Si, (e) and (f) Al-Mn-5Si fracture surface.

Al-based alloys, Guo et al. [25], Lapin and Mareček [26] for NiAl-based alloys. However, this exponent value is lower than the values of 0.14 and 0.15 reported by Lapin et al. [30] and Fan et al. [31] for TiAl-based alloys, respectively. Figure $7 \mathrm{~b}$ shows the values of UTS as a function of $C_{\mathrm{o}}$. The highest UTS value is obtained for the Al-1.94Mn-5Si alloy. The UTS values increase from 59.4 to $122.9 \mathrm{MPa}$, approximately by $51 \%$.

Consequently, the microhardness and ultimate tensile strength of the alloys increase with the increasing $V$ and $C_{\mathrm{o}}$. Especially, the Al-1.94Mn-5Si alloy would be expected to have the highest microhardness and ul- timate tensile strength. Presence of $\mathrm{AlSi}_{5}$ IMC phases throughout the matrix $(\alpha-\mathrm{Al})$ formed along the interdendritic region improves the microhardness and ultimate tensile strength of the matrix.

\subsection{Fracture behavior}

Figure 8 shows the fracture surfaces of the Al$-1.94 \mathrm{Mn}-x \mathrm{Si}$ alloys for the lowest growth velocity $\left(8.3 \mu \mathrm{m} \mathrm{s}^{-1}\right)$. As shown in Fig. $8 \mathrm{~b}$, the fracture surfaces exhibit a lot of dimples indicating the ductile type of fracture. However, the brittle fracture feature 
becomes more evident when the $\mathrm{Si}$ content increases from 0.5 to 5 wt.\%. As apparent from Fig. 8f, there are some cleavage planes and voids marked with white arrows. Many micro-cracks start from these voids (white arrow). As can be seen from these fractographs, the elongation decreases with the increasing Si content. In particular, in the $\mathrm{Al}-1.94 \mathrm{Mn}-1.5 \mathrm{Si}$ and $\mathrm{Al}-$ $-1.94 \mathrm{Mn}-5 \mathrm{Si}$ alloys, the mode of fracture significantly changed from less brittle to more brittle. An important factor that causes brittle fracture is grain size. As grains get smaller, the fracture becomes more brittle. As seen in Figs. 8c,d, numerous cavities are formed on the fracture surface.

\subsection{Electrical properties}

The electrical resistivity of the alloys is affected by microstructure, plastic deformation, heat treatment, temperature, and chemical composition [32]. The growth velocity and temperature dependence of electrical resistivity for Al-Mn- $x \mathrm{Si}$ alloys were measured by the four-point probe method [33]. A sourcemeter (Keithley 2400) and a multimeter (Keithley 2700) were used to provide current and the potential drop. Platinum wires with a diameter of $0.5 \mathrm{~mm}$ were used as current and potential probes. The voltage drop was detected, and electrical resistivity and conductivity were determined using a standard conversion method. The results of the electrical resistivity measurements are presented in Fig. 9. Figure 9a shows the variation of electrical resistivity versus growth velocity and $\mathrm{Si}$ content. Dependence of electrical resistivity on growth velocity can be represented as:

$$
\rho=k_{4} V^{d}
$$

where $k_{4}$ is the constant and $d$ is the exponent of the growth velocity.

As seen in Fig. 9a, the values of $\rho$ increase with the increasing $V$ values. It is found that the increase growth velocity from 8.3 to $978 \mu \mathrm{m} \mathrm{s}^{-1}$ leads to an increase in electrical resistivity from $3.97 \times 10^{-8}$ to $5.49 \times 10^{-8} \Omega \mathrm{m}$ for $0.5 \mathrm{Si}$, from $4.66 \times 10^{-8}$ to $6.52 \times 10^{-8} \Omega \mathrm{m}$ for $1.5 \mathrm{Si}$, and from $5.58 \times 10^{-8}$ to $8.77 \times 10^{-8} \Omega \mathrm{m}$ for $5 \mathrm{Si}$ alloys. The exponent values $d$ are found to be $0.07,0.07$, and 0.09 for $0.5 \mathrm{Si}, 1.5 \mathrm{Si}$, and 5Si alloys, respectively. The exponent values of $d$ obtained in this study are in good agreement with the values ranging from 0.07 to 0.09 reported by Böyük [33] for Al-Si-Ni eutectic, Çadırlı et al. [28], and Kaya et al. $[13,34,35]$ for Al-Ni alloys.

As shown in Fig. 9a, the resistivity increases with the increasing Si content. At the growth velocity of $8.3 \mu \mathrm{m} \mathrm{s}^{-1}$, the experimental values of $\rho$ are measured to be $(3.97,4.66$, and 5.58$) \times 10^{-8} \Omega \mathrm{m}$ for the $0.5 \mathrm{Si}$, $1.5 \mathrm{Si}$, and $5 \mathrm{Si}$ alloys, respectively, at room temperature. The values of electrical resistivity were deter-
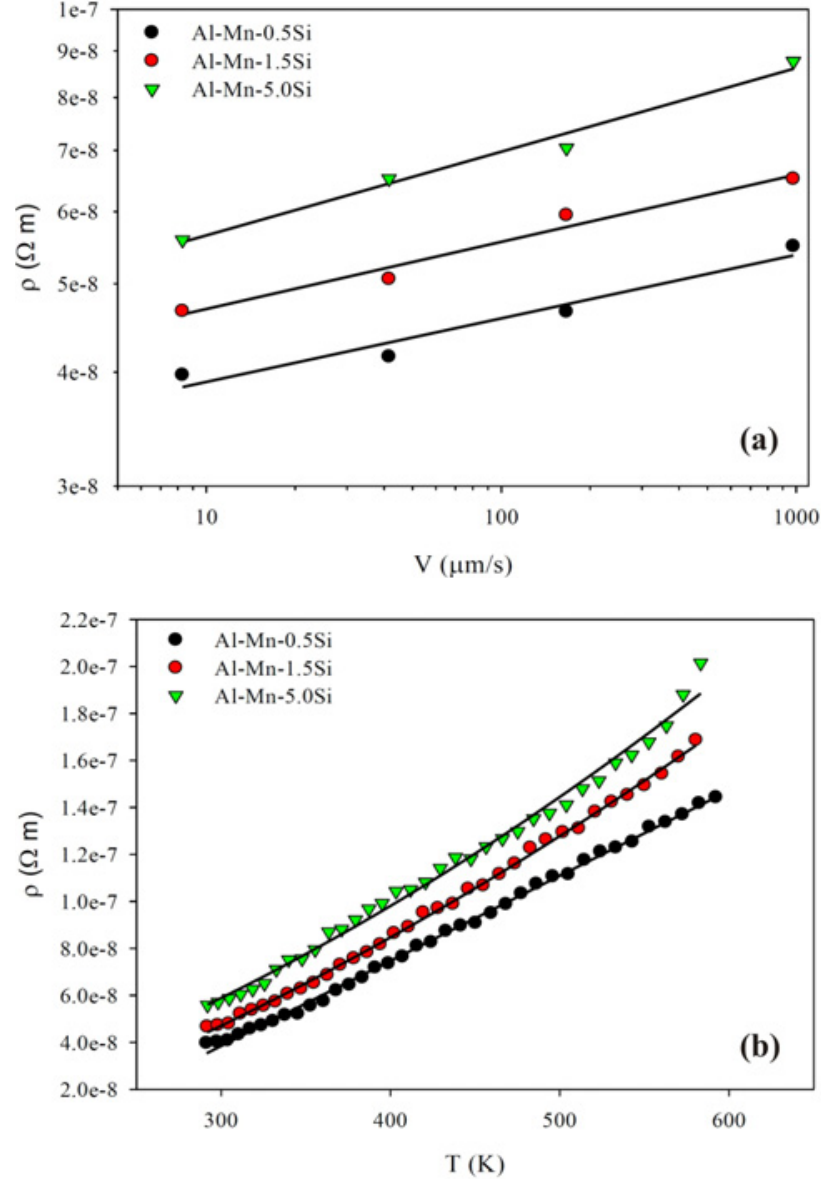

Fig. 9. Variation of electrical resistivity versus growth velocity (a) and variation of electrical resistivity versus temperature (b).

mined in the temperature interval of 293-592 $\mathrm{K}$ and the data are plotted in Fig. $9 \mathrm{~b}$. The $\rho$ values increase linearly with the increasing $T$ values for each alloy and increase with the increasing Si content. The similar trend is supported by the previous results of Kaya [5], Boekelheide et al. [36], and Çadırlı et al. [37]. The electrical resistivity was determined to increase from $3.97 \times 10^{-8}$ to $20.07 \times 10^{-8} \Omega \mathrm{m}$ with the increasing temperature from 293 to $592 \mathrm{~K}$.

\subsection{Thermal properties}

The Al-Mn- $x$ Si alloys were heated with a heating velocity of $10 \mathrm{~K} \mathrm{~min}^{-1}$ from room temperature to $1000 \mathrm{~K}$ by using a Perkin Elmer Diamond model DSC. The corresponding heat flow versus temperature curves are shown in Fig. 10. The melting temperatures were detected to be $944.7,926.8$, and $862.7 \mathrm{~K}$ for the $0.5 \mathrm{Si}, 1.5 \mathrm{Si}$, and $5 \mathrm{Si}$ alloys, respectively. The values of the enthalpy of fusion were calculated to be $185.5,123.8$, and $89.3 \mathrm{~J} \mathrm{~g}^{-1}$ for the $0.5 \mathrm{Si}, 1.5 \mathrm{Si}$, and $5 \mathrm{Si}$ alloys, respectively. The values of the spe- 


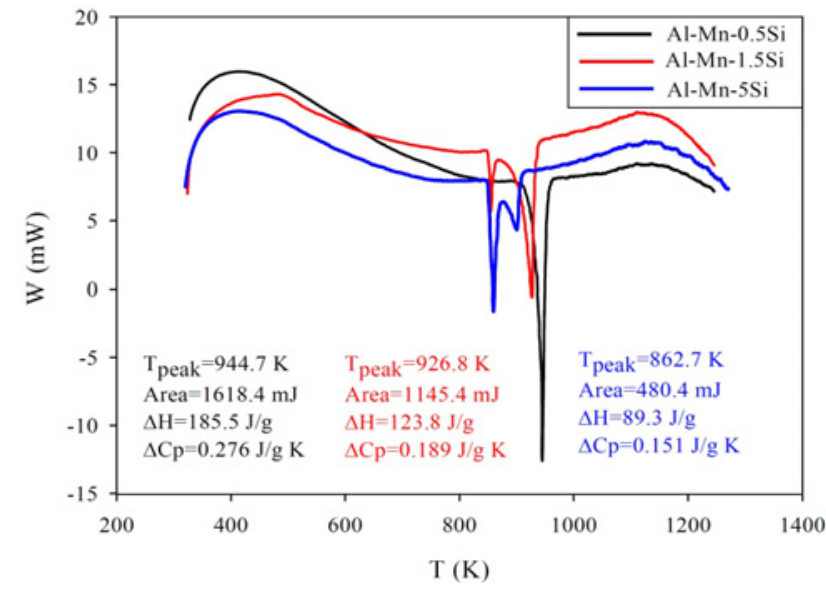

Fig. 10. Heat flow curves for Al-Mn- $x$ Si alloys at a heating velocity of $10 \mathrm{~K} \mathrm{~min}^{-1}$.

cific heat capacity were also calculated to be 0.276 , 0.189 , and $0.151 \mathrm{~J} \mathrm{~g}^{-1} \mathrm{~K}^{-1}$ for the $0.5 \mathrm{Si}, 1.5 \mathrm{Si}$, and $5 \mathrm{Si}$ alloys, respectively. As shown in Fig. 10 and results from the calculated results, the melting temperature of Al-1.94Mn alloys increases, but $\Delta H$ and $C_{\mathrm{p}}$ values decrease with the increasing $\mathrm{Si}$ content. The recommended values of $\Delta H$ for pure $\mathrm{Al}, \mathrm{Mn}$, and $\mathrm{Si}$ are $396.9,240.3$, and $235 \mathrm{~J} \mathrm{~g}^{-1}$, respectively [38]. The specific heat capacity values for pure $\mathrm{Al}, \mathrm{Mn}$, and $\mathrm{Si}$ are $0.879,0.48$, and $0.711 \mathrm{~J} \mathrm{~g}^{-1} \mathrm{~K}^{-1}$ at the melting temperature, respectively [38]. The values of $\Delta H$ $\left(89.3-185.5 \mathrm{~J} \mathrm{~g}^{-1}\right)$ in this work are smaller than the $\Delta H$ values of the pure Al, Mn, and Si. Similarly, the calculated specific heat capacity values $(0.151-0.276$ $\left.\mathrm{J} \mathrm{g}^{-1} \mathrm{~K}^{-1}\right)$ in this work are much smaller than the $C_{\mathrm{p}}$ values of $0.879,0.48$, and $0.711 \mathrm{~J} \mathrm{~g}^{-1} \mathrm{~K}^{-1}$ for the pure $\mathrm{Al}, \mathrm{Mn}$, and $\mathrm{Si}$, respectively.

\section{Conclusions}

The effects of growth velocity and Si content on the microstructure, mechanical, electrical, and thermal properties of Al-1.94Mn- $x \mathrm{Si}(x=0.5,1.5,5 \mathrm{wt} . \%)$ $\mathrm{Si}$ alloys have been investigated in this research. The principal results can be summarized as follows:

1. The primary dendrite arm spacing of Al-1.94Mn$-x \mathrm{Si}$ alloys decreases with the increasing growth velocity and increases with the increasing Si content.

2. The Vickers microhardness values $\mathrm{HV}$ increase from 326 to $468 \mathrm{MPa}$ with the increasing growth velocity from 8.3 to $978 \mu \mathrm{m} \mathrm{s}^{-1}$. At a constant growth velocity of $8.3 \mu \mathrm{m} \mathrm{s}^{-1}$, the values $\mathrm{HV}$ increase from 326 to $367 \mathrm{MPa}$ with the increasing Si content from 0.5 to 5 wt. $\%$.

3. Depending on Si content, the increasing growth velocity $V$ from 8.3 to $978.0 \mu \mathrm{m} \mathrm{s}^{-1}$ leads to an increase of ultimate tensile strength values from 59 to $165 \mathrm{MPa}$.
4. The values of $\rho$ increase with the increasing growth velocity. It was found that the values of electrical resistivity change with the $\mathrm{Si}$ content. While the maximum $\rho$ value of $5.58 \times 10^{-8} \Omega \mathrm{m}$ is measured for Al-Mn-5Si alloy, the minimum $\rho$ value of $3.97 \times 10^{-8} \Omega \mathrm{m}$ is measured for Al-Mn-0.5Si alloy.

5 . The melting temperatures of the Al-1.94Mn- $x \mathrm{Si}$ alloys are found to be $944.7,926.8$, and $862.7 \mathrm{~K}$ for $x=0.5,1.5$, and $5 \mathrm{wt} . \%$, respectively. The values of the melting temperature, enthalpy of fusion, and the specific heat capacity decrease with the increasing $\mathrm{Si}$ content.

\section{Acknowledgements}

This research was financially supported by the Scientific and Technical Research Council of Turkey (TUBITAK) under contract no. 212T130. The authors are grateful to TUBİTAK.

\section{References}

[1] S. W. Nam, D. H. Lee, The effect of Mn on the mechanical behavior of Al alloys, Metals and Materials 6 (2000) 13-16. doi:10.1007/BF03026339

[2] A. Bahadur, Intermetallic phases in Al-Mn alloys, J. Mat. Sci. 23 (1988) 48-54. doi:10.1007/BF01174033

[3] D. M. J. Wilkes, H. Jones, Structure and properties of rapidly-solidified Al-rich Al-Mn-Si alloys Part II Atomized powder, its extrudate and the effect of blended-in SiC, J. Mat. Sci. 34 (1999) 749-761. doi:10.1023/A:1004564611541

[4] T. C. Rollason, J. W. Martin, The effect of particle size upon the annealing behaviour of plastically deformed two-phase crystals, J. Mater. Sci. 5 (1970) 127-132. doi:10.1007/BF00554630

[5] H. Kaya, Dependency of electrical resistivity on the temperature and composition of $\mathrm{Al}-\mathrm{Cu}$ alloys, Mater. Res. Innov. 16 (2012) 224-229. doi:10.1179/1433075X11Y.0000000041

[6] D. G. McCartney, Grain refining of aluminum and its alloys using inoculants, Int. Mat. Rev. 34 (1989) 247260. doi:10.1179/imr.1989.34.1.247

[7] H. Kaya, A. Aker, Effect of alloying elements and growth velocities on microstructure and mechanical properties in the directionally solidified Al-Si-X alloys, J. Alloys Comp. 694 (2017) 145-154. doi:10.1016/j.jallcom.2016.09.199

[8] H. S. Kang, W. Y. Yoon, K. H. Kim, M. H. Kim, Y. P. Yoon, I. S. Cho, Effective parameter for the selection of modifying agent for $\mathrm{Al}-\mathrm{Si}$ alloy, Mat. Sci. Eng. A 449-451 (2007) 334-337. doi:10.1016/i.msea.2006.01.166

[9] U. Hecht, L. Granasy, T. Pusztai, B. Bottger, M. Apel, V. Witusiewicz, L. Ratke, J. De Wilde, L. Froyen, D. Camel, B. Drevet, G. Faivre, S. G. Fries, B. Legendre, S. Rex, Multiphase solidification in multicomponent alloys, Mater. Sci. Eng. R 46 (2004) 1-49. doi:10.1016/j.mser.2004.07.002 
[10] T. T. Shun, L. Y. Chang, M. H. Shiu, Microstructure and mechanical properties of multiprincipal component $\mathrm{CoCrFeNiMo}_{\mathrm{x}}$ alloys, Mater. Charact. 70 (2012) 63-67. doi:10.1016/i.matchar.2012.05.005

[11] Y. X. Zhuang, W. J. Liu, Z. Y. Chen, H. D. Xue, J. C. He, Effect of elemental interaction on microstructure and mechanical properties of $\mathrm{FeCoNi}-$ CuAl alloys, Mater. Sci. Eng. A 556 (2012) 395-399. doi:10.1016/i.msea.2012.07.003

[12] R. Trivedi, W. Kurz, Dendritic growth, Int. Mat. Rev. 39 (1994) 49-74. doi:10.1179/imr.1994.39.2.49

[13] A. Aker, H. Kaya, Measurements of microstructural, mechanical, electrical and thermal properties of an Al-Ni alloy, I. J. Thermophysics 34 (2013) 267-283. doi:10.1007/s10765-013-1401-7

[14] J. Fan, X. Li, Y. Su, J. Guo, H. Fu, The microstructure parameters and microhardness of directionally solidified Ti-43Al-3Si alloy, J. Alloys Comp. 506 (2010) 593-599. doi:10.1016/j.jallcom.2010.07.122

[15] M. S. Bhat, D. R. Poirier, J. C. Heinrich, A Permeability length scale for cross flow through model structures, Metall. Trans. B 26(1995) 1049-1056. doi:10.1007/BF02654107

[16] P. Robinson, Practical Specific Heat Determination by Power Compensation DSC, Perkin Elmer technical note, Perkin Elmer, Seer Green, 2003.

[17] J. Fan, X. Li, Y. Su, R. Chen, J. Guo, H. Fu, Directional solidification of Ti-49at.\%Al alloy, App. Phys. A 105 (2011) 239-248. doi:10.1007/s00339-011-6497-7

[18] J. Lapin, Z. Gabalcová, Solidification behaviour of TiAl-based alloys studied by directional solidification technique, Intermetallics 19 (2011) 797-804. doi:10.1016/j.intermet.2010.11.021

[19] H. Kaya, E. Çadırlı, M. Gündüz, Directional cellular growth of Al-2wt.\%Li bulk samples, Applied Physics A 94 (2009) 155-165. doi:10.1007/s00339-008-4714-9

[20] H. Kaya, E. Çadırlı, M. Gündüz, Dendritic growth in an aluminum-silicon alloy, J. Mater. Eng. Perf. 16 (2007) 12-21. doi:10.1007/s11665-006-9002-2

[21] J. D. Hunt, Solidification and casting of metals, The Metal Society, London, 1979.

[22] W. Kurz, D. J. Fisher, Dendritic growth and limit of stability tip radius and spacing, Acta Metall. 29 (1981) 11-20. doi:10.1016/0001-6160(81)90082-1

[23] R. Trivedi, Interdendritic spacing: Part II. A comparison of theory and experiment, Met. Trans. A 15 (1984) 977-982. doi:10.1007/BF02644689

[24] H. Kaya, E. Çadırlı, M. Gündüz, A. Ülgen, Effect of the temperature gradient, growth velocity, and the interflake spacing on the microhardness in the directionally solidified Al-Si eutectic alloy, J. Mat. Eng. Perf. 12 (2003) 544-551. doi:10.1361/105994903100277201

[25] J. T. Guo, C. M. Xu, X. H. Du, H. Z. Fu, The effect of solidification velocity on microstructure and mechanical properties of an eutectic NiAl-Cr(Mo)-Hf alloy, Mater. Lett. 58 (2004) 3233-3236. doi:10.1016/i.matlet.2004.02.047
[26] J. Lapin, J. Mareček, Effect of growth velocity on microstructure and mechanical properties of directionally solidified multiphase intermetallic Ni-Al-Cr-Ta-Mo-Zr alloy, Intermetallics 14 (2006) 1339-1344. doi:10.1016/j.intermet.2005.10.016

[27] F. Perdrix, M. F. Trichet, J. L. Bonnentien, M. Cornet, J. Bigot, Influence of cooling velocity on microstructure and mechanical properties of a Ti-48Al alloy, Intermetallics 7 (1999) 1323-1328. doi:10.1016/S0966-9795(99)00016-3

[28] E. Çadırlı, I. Yılmazer, M. Şahin, H. Kaya, Investigation of some physical properties of the directionally solidified Al-Cu-Co ternary eutectic alloy. Trans. Indian Inst. Metals 68 (2015) 817-827. doi:10.1007\%2Fs12666-015-0515-y

[29] U. Büyük, S. Engin, H. Kaya, E. Çadırlı, N. Maraşlı, Directionally solidified Al-Cu-Si-Fe quaternary eutectic alloys, Phys. Metals Metall. 121 (2020) 78-83. doi:10.1134/S0031918X20010044

[30] J. Lapin, L'. Ondrúš, M. Nazmy, Directional solidification of intermetallic Ti-46Al-2W-0.5Si alloy in alumina moulds, Intermetallics 10 (2002) 1019-1031. doi:10.1016/S0966-9795(02)00119-X

[31] J. Fan, X. Li, Y. Su, J. Guo, H. Fu, Dependency of microhardness on solidification processing parameters and microstructure characteristics in the directionally solidified Ti-46Al-0.5W-0.5Si alloy, J. Alloys Comp. 504 (2010) 60-64. doi:10.1016/i.jallcom.2010.05.095

[32] F. M. Smits, Measurement of sheet resistivities with the four-point probe, AT\&T Tech J. 37 (1958) 711718. doi:10.1002/j.1538-7305.1958.tb03883.x

[33] U. Böyük, Physical and mechanical properties of AlSi-Ni eutectic alloy, Met. Mater. Int. 18 (2012) 933938. doi:10.1007/s12540-012-6004-5

[34] H. Kaya, U. Böyük, E. Çadırlı, N. Maraşlı, Measurements of the microhardness, electrical and thermal properties of the Al-Ni eutectic alloy, Mat. Design 34 (2012) 707-712. doi:10.1016/j.matdes.2011.05.030

[35] H. Kaya, U. Böyük, E. Çadırlı, N. Maraşlı, Influence of growth velocity on microstructure, microhardness, and electrical resistivity of directionally solidified Al7 wt.\%Ni hypo-eutectic alloy, Met. Mater. Int. 19 (1) (2013) 39-44. doi:10.1007/s12540-013-1007-4

[36] Z. Boekelheide, D. W. Cooke, E. Helgren, F. Hellman, Resonant impurity scattering and electron-phonon scattering in the electrical resistivity of $\mathrm{Cr}$ thin films, Phys. Rev. B 80 (2009) 134426. doi:10.1103/PhysRevB.80.134426

[37] E. Çadırlı, U. Büyük, S. Engin, H. Kaya, Effect of silicon content on microstructure, mechanical and electrical properties of the directionally solidified Al based quaternary alloys, J. Alloy and Comp. 694 (2017) 471479. doi:10.1007/s11661-017-4337-x

[38] R. Hultgren, P. D. Desai, D. T. Hawkins, M. Gleiser, K. K. Kelly, D. D. Wagman, Selected Values of the Thermodynamic Properties of the Elements, ASM, Metal Park, 1973, OH, USA. ASIN: B000O7IWHC 